\title{
LA COMPETENCIA MEDIÁTICA A TRAVÉS DE LOS CONTENIDOS CURRICULARES EN LA ETAPA DE EDUCACIÓN PRIMARIA EN ESPAÑA*
}

\author{
Antonia Ramírez García ${ }^{1}$ \\ Paula Renés Arellano ${ }^{2}$ \\ Natalia GonZález Fernández ${ }^{1}$
}

\begin{abstract}
RESUMEN: En este artículo se revisó el currículo del cuarto curso de educación primaria en la normativa de todas las comunidades autónomas de España para comprobar la presencia o ausencia de la competencia mediática en el documento. El método utilizado fue el análisis de contenido. Los resultados muestran que todas las dimensiones de la competencia mediática quedan reflejadas en dichos contenidos. Asimismo, en todas las áreas del currículo, se aprecia una relación entre los descriptores de la competencia mediática y los contenidos curriculares.
\end{abstract}

Palabras clave: Competencia mediática. Medios de comunicación. Currículum. Educomunicación.

\section{MEDIA LITERACY THROUGH CURRICULAR CONTENT ON THE PRIMARY EDUCATION STAGE IN SPAIN}

ABSTRACT: In this paper, we analyzed the curriculum of the fourthyear of primary education in the laws of all the autonomous regions of Spain to verify the presence or absence of the media competence in such document. The analysis of content was used as the main method. The results show that all dimensions of the media competence are in the above-mentioned contents. In addition, in all the curriculum areas, a relation is seen between the descriptors of the media competence and the curricular contents.

Keywords: Media literacy. Means of communication. Curriculum. Media education.

\footnotetext{
*El presente artículo es resultado del "Proyecto I+D "La enseñanza obligatoria ante la competencia en comunicación audiovisual en un entorno digital (EDU2010-21395-C03-03)", que recibió soporte financiero del Ministerio de Economía y Competitividad.

${ }^{1}$ Universidad de Córdoba, Facultad de Ciencias de la Educación, Área de Métodos de Investigación y Diagnóstico en Educación, Departamento de Educación - Córdoba, España. E-mail: ed1 ragaa@uco.es ${ }^{2}$ Universidad de Cantabria, Facultad de Educación, Departamento de Educación - Cantabria, Espańa. E-mail: renesp@unican.es DOI: 10.1590/ES0101-73302016128894
} 


\title{
LA CONCURRENCE MÉDIATIQUE PAR LE CONTENU DU PROGRAMME SUR LA SCENE DE L'ENSEIGNEMENT PRIMAIRE EN ESPAGNE
}

\begin{abstract}
RÉSUMÉ: Dans cet article on révise le curriculum du quatrième cours d'Instruction primaire dans les lois de toutes les communautés autonomes de l'Espagne pour vérifier la présence ou l'absence de la concurrence médiatique dans elle. La méthode utilisée a été l'analyse de contenu. Les résultats montrent que toutes les dimensions de la concurrence médiatique sont présentes dans ces contenus. De la même manière, dans toutes les aires du curriculum une relation est vue entre les descripteurs de la concurrence médiatique et les contenus des programmes d'enseignement.
\end{abstract}

Mots-clés: Concurrence médiatique. Moyens de communication. Curriculum. Éducation aux médias.

\section{Introducción}

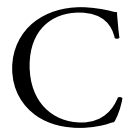

ada mañana cuando leemos el periódico o escuchamos la radio, no resulta extrańo encontrar alguna noticia o referencia a la necesidad de ofrecer a los mercados productos de calidad, de mejorar la calidad de los servicios prestados por las empresas o de incrementar los niveles de calidad de la sanidad, de la administración pública, de la educación, entre otros ámbitos.

Para Arnaiz y de Haro (2004, p. 21), una educación de calidad ha de "conectar el mundo escolar con las necesidades de la sociedad del siglo XXI, lo que exige replantear y reconstruir nuestro sistema educativo". Esto conlleva inexorablemente a una reforma, por ello, desde finales del siglo XX, se aprecia en el ámbito internacional una importante corriente de reformas que afecta de forma directa al currículo de diferentes sistemas educativos. Así, los distintos países de la Unión Europea han tratado de buscar y encontrar fórmulas de diseño curricular que puedan conciliar las demandas y los intereses de cada comunidad educativa con los más generales de sus respectivos contextos locales, regionales-autonómicos y nacionales. De este modo, nuevos parámetros tratan de adaptar los currículos a las necesidades y exigencias de las sociedades contemporáneas, con el fin de contribuir a la formación integral del ciudadano (ORTIZ, 2009), entre ellos la incorporación de las competencias básicas.

Desde diferentes campos como la sociología, educación, filosofía, psicología, antropología o economía, se ha intentado definir el concepto de competencia, término que en nuestro sistema educativo se incorporó con la reforma de la Formación Profesional hace algunas décadas, aunque ha cobrado más relevancia a partir de la publicación de la Ley Orgánica de la Educación (LOE) 2/2006 (ESPAÑA, 2006a), en 3 de mayo de 2006. Para Zabala y Arnau (2008, p. 45), 
teniendo presente la definición de la Organización para la Cooperación y el Desarrollo Académico/Design and Selection of Competencies (OCDE-DESECO, 2002):

[...] la competencia ha de identificar aquello que necesita cualquier persona para dar respuesta a los problemas a los que se enfrentará a lo largo de su vida. Por tanto, competencia consistirá en la intervención eficaz en los diferentes ámbitos de la vida mediante acciones en las que se movilizan, al mismo tiempo y de manera interrelacionada, componentes actitudinales, procedimentales y conceptuales.

A pesar de que se han contabilizado más de cien definiciones sobre la 'competencia', De la Orden (2011, p. 10) manifestó la dificultad de plantear un cuerpo teórico sobre el término competencia, pues, a pesar de la preocupación generalizada,

[...] la actual literatura sobre competencias carece de una base conceptual y analítica y no existe un reconocimiento explícito de la necesidad de programas de investigación tendentes a promover una mejor comprensión de la naturaleza de la competencia, cómo desarrollarla en los alumnos, cómo puede ser evaluada y cuál puede ser el impacto que tendría en los estudiantes, en las organizaciones educativas y en la sociedad en general.

Aun sin un cuerpo teórico reconocido, las competencias se han instalado en nuestro currículo oficial bajo la denominación de 'competencias básicas', que es fruto de la "Recomendación del Parlamento Europeo y del Consejo de 18 de diciembre de 2006 sobre las competencias clave para el aprendizaje permanente" (UNIÓN EUROPEA, 2006/962/CE). Esta estableció las competencias básicas, posteriormente recogidas en la LOE (ESPAÑA, 2006a) y desarrolladas mediante el Real Decreto 1513/06 (ESPAÑA, 2006b) de 7 de diciembre, incluyendo: la competencia en comunicación lingüística, matemática, conocimiento e interacción con el mundo físico; el tratamiento de la información y competencia digital, social y ciudadana, cultural y artística, para aprender a aprender; la autonomía e iniciativa personal.

Desde este momento, defensores de muchas otras competencias han intentado que estas también sean consideradas básicas, tal es el caso de la competencia mediática, de aquella en medios de comunicación, de la competencia en comunicación o competencia audiovisual (en las conferencias del II Congreso Media Literacy in Europe: Controversies, challenges and perspectives, Bazalgette, Bevort, Buckingham, Carlsson, Piette, Tisseron o Verniers, en 2009). En este sentido, Buckingham (2009 apud AGUADED et al., 2011) detalló incluso los aspectos distintivos que la definirían: habilidades en el manejo de la tecnología; aprecio de la herencia europea audiovisual; protección de los niños ante contenidos nocivos y desarrollo de su conciencia ante los riesgos en la red; inclusión de grupos que fueron excluidos en el uso de la tecnología; resistencia a la persuasión comercial y sensibilización en la comercialización de nuevas prácticas; fomento 
de la ciudadanía activa y participación en la sociedad civil; promoción de la libre creatividad y la expresión artística mediante el uso de nuevos medios de comunicación y posibilidad de comunicación con el público.

Como consecuencia de este movimiento, Ferrés, en 2007, publicó el documento "Competencias en comunicación audiovisual", definiendo la competencia en comunicación audiovisual como "la capacidad del individuo para interpretar y analizar desde la reflexión crítica las imágenes y los mensajes audiovisuales y para expresar con una mínima corrección en el ámbito comunicativo" (FERRÉS, 2007, p. 102). Por su parte, González, Sedeño y Gonzálvez (2012, p. 122) consideran que

la competencia audiovisual está íntimamente relacionada con la competencia mediática, de modo que pueden incluso identificarse ambas categorías en un entorno en el que es fundamental el conocimiento de los medios de comunicación y de las tecnologías multimedia.

Como resultados de la preocupación europea por contar con ciudadanos alfabetizados mediáticamente que analicen de forma crítica las informaciones que les presentan los medios de comunicación en sus distintos formatos ${ }^{1}$, diversas autorías han desarrollado investigaciones para conocer el grado de competencia mediática de la ciudadanía andaluza (AGUADED et al., 2011), aragonesa (GABELAS; MARTA, 2011) y/o española, en su conjunto (FERRÉS et al., 2011). Las conclusiones de esos investigadores muestran una urgente educación en medios de comunicación en las seis dimensiones propuestas por Ferrés (2007) y Ferrés y Piscitelli (2012), en las que se establecen dos ámbitos de acción, el del análisis, vinculado a la participación como personas que reciben mensajes e interacciones con ellos, y el de la expresión, relacionado con la producción de mensajes.

\section{Material y método}

La estructura educativa actual en España (ESPAÑA, 2013) enmarca las etapas educacionales de enseñanza primaria (6 hasta 12 años) y educación secundaria obligatoria (12 hasta 16 ańos) como los dos pilares en los que se establece la educación obligatoria. En el marco de las seis dimensiones indicadas, o sea, lenguajes, tecnología, procesos de interacción, procesos de producción y difusión, ideología y valores y estética, y sus respectivos indicadores, es en el que se ha llevado a cabo una revisión del currículo establecido en la normativa actual de las comunidades autónomas españolas, al objeto de comprobar la presencia o la ausencia de la competencia mediática en el currículo de la educación primaria, concretamente en el su segundo ciclo. La finalidad de centrarse en este está determinada por ser en ese momento en el que el alumnado realiza las pruebas de evaluación nacionales para determinar su nivel competencial en diversas áreas curriculares. 
Esta revisión se ha realizado para diseñar el marco teórico del Proyecto I+D "La enseñanza obligatoria ante la competencia en comunicación audiovisual en un entorno digital (EDU2010-21395-C03-03)", punto de partida para la elaboración de un cuestionario tendente a medir la competencia mediática del alumnado del cuarto de educación primaria ${ }^{2}$.

El interrogante de investigación propuesto parte de una serie de afirmaciones realizadas por distintos autores (APARICI et al., 2010; CAMPS, 2009; TU$\mathrm{CHO}, 2008)$ sobre la escasa presencia de la competencia mediática en el currículo de las etapas de enseñanza obligatoria. Pero ¿̇cuál es la presencia real de la competencia mediática en el currículo del alumnado del cuarto de la educación primaria? Las fases seguidas para determinar esta presencia se han plasmado en la Figura 1.

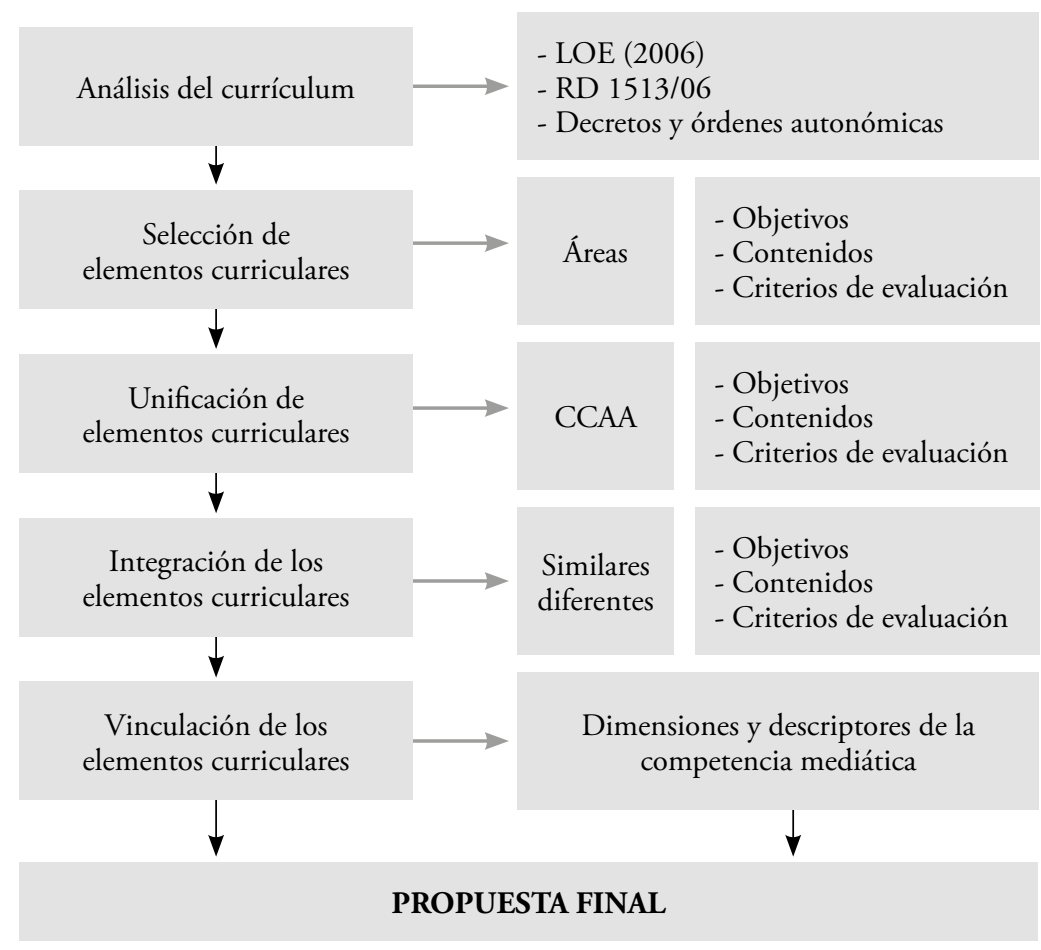

Figura 1

Proceso de vinculación.

El método utilizado en esta investigación se ha centrado en un estudio cualitativo, concretamente en un análisis documental descriptivo. La rigurosidad y sistematicidad han caracterizado cada una de las fases; en este sentido, la que mayor dificultad presentó fue la elaboración de una propuesta final en la que se relacionaban los descriptores de la competencia mediática con los contenidos del currículo del cuarto de la educación primaria. 
Los contenidos constituyen un elemento curricular de gran trascendencia, ya que han de ser concretados por los docentes en su programación de aula, estableciendo la base para el diseńo y el desarrollo de actividades posteriores. La presencia o ausencia de los aspectos distintivos de la competencia mediática en ellos puede manifestar la necesidad de incorporar, legislativamente, una mayor alfabetización en medios o reconducir la mirada hacia las aulas de educación primaria.

La labor de las autoras se ha centrado fundamentalmente en las cuatro primeras fases, debido a su especialización en educación y medios de comunicación. Primeramente, hubo la codificación de las unidades de registro atendiendo a la comunidad autónoma, al número de orden de la normativa y al elemento curricular. Después se seleccionaron los contenidos curriculares. La segunda fase fue establecer índices de búsqueda para diferenciar los contenidos curriculares que hacían referencia a la competencia mediática, y finalmente su vinculación con las diversas dimensiones. En última instancia, se realizó un análisis comparativo de los datos obtenidos para mejor determinar las unidades de registro, recodificación y análisis final. Todo ello fue analizado a través del programa ATLAS.ti, versión 6 (ATLAS.ti Scientific Software Development GmbH). En la quinta fase, junto a las autoras, han participado diez maestros y maestras de educación primaria en ejercicio ${ }^{3}$, focalizando su actuación en la vinculación de los descriptores de la competencia mediática con los contenidos del currículo. La propuesta presentada fue llevada a cabo considerando que la vinculación entre los elementos se produjera, al menos, en el $70 \%$ de las respuestas dadas por los participantes.

\section{Resultados}

Diversas autorías, como ya se ha señalado, han manifestado que la competencia mediática se caracteriza por una escasa presencia en el currículo. No obstante, esta afirmación requiere explicitarlo con evidencias concretas y ese ha sido el objetivo de esa investigación, pues, si bien es cierto que la competencia mediática no aparece como tal, muchos de sus descriptores sí se encuentran presentes en el currículo, tal y como tendremos ocasión de comprobar. Al segmentar las dimensiones de la competencia mediática, Ferrés (2007) estableció 55 descriptores que mostraban la competencia digital, de ellos 36 fueron identificados en los contenidos de las áreas que integran el currículum del cuarto curso de la educación primaria: conocimiento del medio $(\mathrm{CM})$; educación artística $(\mathrm{EA})$; educación física $(\mathrm{EF})$; lengua castellana (LC); lengua extranjera (LE) y matemáticas (MA). Este número supone que el $65,45 \%$ de los aspectos distintivos de la competencia digital se encuentra en dicho currículum, pero cómo se encuentra distribuida dicha presencia. La Figura 2 presenta la comparación entre la propuesta de Ferrés (2007) y los contenidos curriculares. Las mayores diferencias entre ambos se observan en tres dimensiones: procesos de interacción, procesos de producción y difusión e ideología y valores. Esto puede ser 


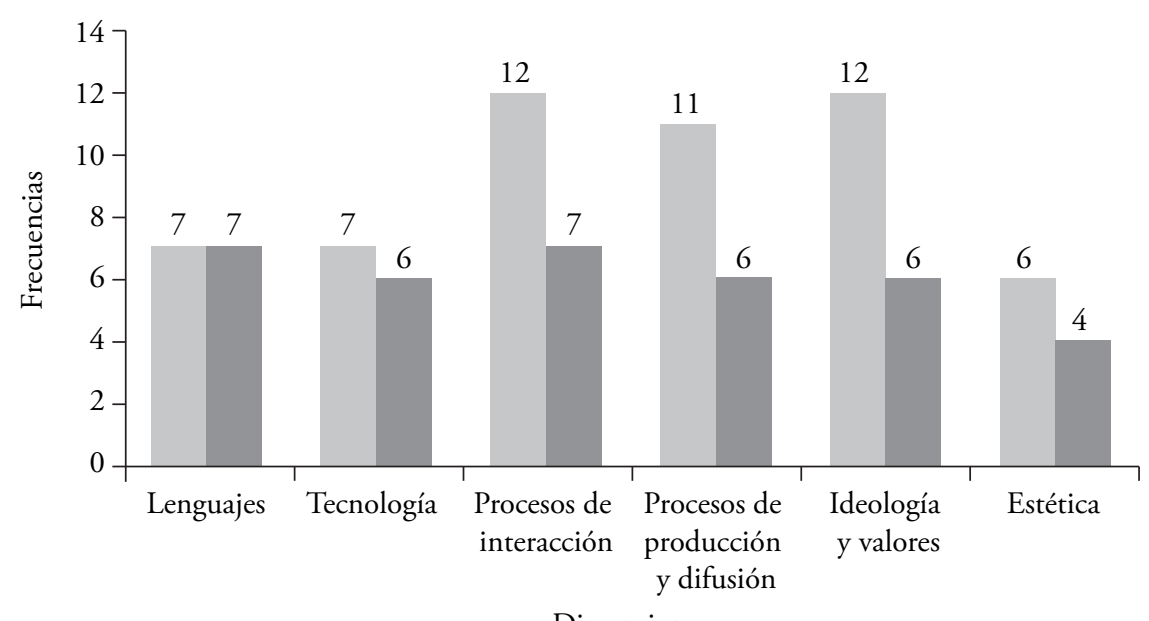

Dimensiones

Competencia Curriculum

\section{Figura 2}

Presencia de los contenidos curriculares en los descriptores de la competencia mediática.

debido a que tradicionalmente han sido las menos conocidas en el ámbito educativo. Cabría señalar también la igualdad que se manifiesta en las dimensiones lenguajes y tecnología; en el primer caso, tradicionalmente más presente en el ámbito educativo en áreas como lengua castellana y literatura y educación artística y, en el segundo, debido posiblemente a la incorporación de la competencia digital al currículo escolar.

Por su parte, en la Figura 3, se destacaron tres aspectos básicos:

- en las dimensiones lenguajes, procesos de interacción e ideologías y valores, predominan los procesos de análisis frente a los procesos de expresión;

- en tecnologías, procesos de producción y difusión y estética, se destacan los procesos de expresión, en contraposición a los del análisis;

- en ideología y valores, solo se contemplan procesos de análisis.

De forma más detallada, en las Tablas 1 a 6 se muestran las frecuencias y los porcentajes de los contenidos de las distintas áreas del currículo del cuarto de educación primaria, relacionados con los descriptores de la competencia mediática en cada una de sus dimensiones.

Las áreas de Lengua castellana (LC), lengua extranjera (LE) y educación artística (EA) son las que mayor presencia manifiestan en la dimensión 'Lenguajes', seguidas de matemáticas (MA) y educación física (EF).

Algunos ejemplos representativos de esta presencia son: 


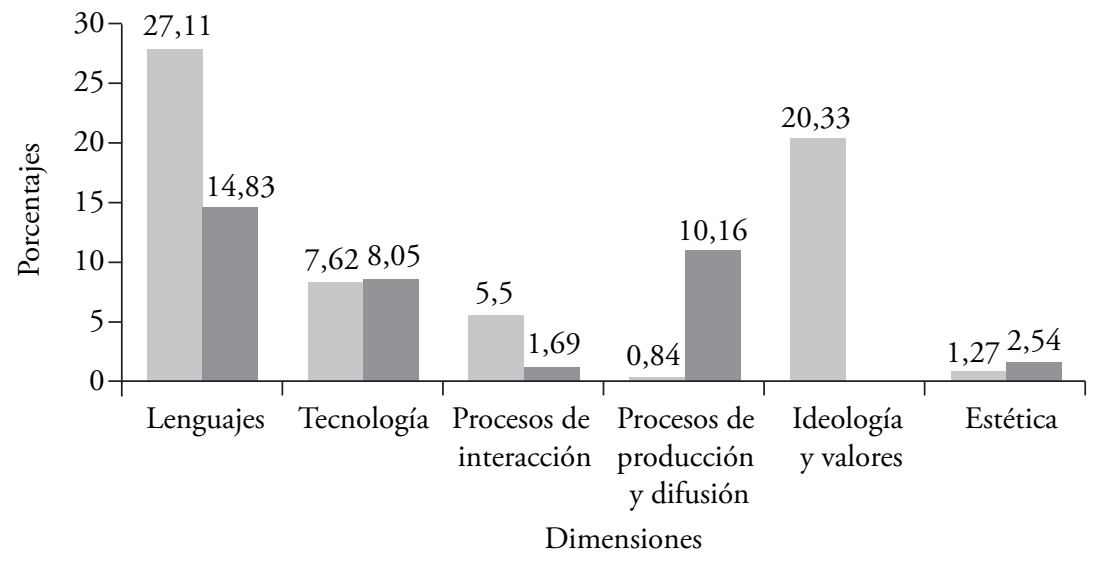

Análisis —Expresión

\section{Figura 3}

Distribución de los contenidos curriculares en función de las dimensiones y sub-dimensiones de la competencia digital.

- CM: comunicación de informaciones con varios lenguajes (L1e);

- EA: análisis y valoración de la intención comunicativa de los nuevos códigos audiovisuales, de las imágenes en los medios y en las tecnologías de la información y la comunicación - TIC (L1a);

- EF: comprensión de la información sobre juegos tradicionales o actuales, instrucciones, deportes en textos escritos o a través de los medios audiovisuales y de las TIC (L3a);

- LC: escucha, comprensión de informaciones audiovisuales procedentes de distintos soportes, estableciendo relaciones entre ellos (identificación, clasificación y comparación, L4a);

- LE: lectura y escritura autónoma de textos en diferentes soportes y adecuados a su edad, nivel de competencia e intereses personales para aprender, disfrutar informar o informarse y compartir con los miembros del grupo (L2e);

- MA: lectura, interpretación y análisis crítico de mensajes que contengan informaciones sobre relaciones espaciales, gráficos estadísticos, pictogramas extraídos de distintos medios (incluidos los medios de comunicación), libros, diarios, Internet y otros (L2a). 


\section{Tabla 1}

Frecuencias y porcentajes totales de los descriptores de la dimensión "Lenguajes".

\begin{tabular}{|c|c|c|c|c|c|c|c|}
\hline Descriptores & $\mathrm{CM}$ & EA & $\mathbf{E F}$ & LC & LE & MA & $\%$ \\
\hline \multicolumn{8}{|l|}{ Análisis } \\
\hline $\begin{array}{l}\text { L1a. Capacidad de interpretar y valorar los } \\
\text { diversos códigos de representación y la función } \\
\text { que ellos cumplen en un mensaje. }\end{array}$ & 0 & 5 & 0 & 3 & 0 & 0 & 3,38 \\
\hline $\begin{array}{l}\text { L2a. Capacidad de analizar y valorar los mensajes } \\
\text { desde la perspectiva del significado y sentido, de } \\
\text { las estructuras narrativas y de las convenciones } \\
\text { de género y formato. }\end{array}$ & 1 & 7 & 0 & 8 & 1 & 1 & 7,62 \\
\hline $\begin{array}{l}\text { L3a. Capacidad de comprender el flujo de historias y } \\
\text { de informaciones procedentes de múltiples medios, } \\
\text { soportes, plataformas y modos de expresión. }\end{array}$ & 1 & 2 & 1 & 7 & 8 & 3 & 9,32 \\
\hline $\begin{array}{l}\text { L4a. Capacidad de establecer relaciones entre } \\
\text { textos (intertextualidad), códigos y medios, } \\
\text { por medio de la elaboración de conocimientos } \\
\text { abiertos, sistematizados e interrelacionados. }\end{array}$ & 1 & 1 & 0 & 5 & 6 & 3 & 6,77 \\
\hline \multicolumn{8}{|l|}{ Expresión } \\
\hline $\begin{array}{l}\text { L1e. Capacidad de expresarse mediante una } \\
\text { amplia gama de sistemas de representación y } \\
\text { significación. }\end{array}$ & 2 & 1 & 0 & 5 & 5 & 1 & 5,93 \\
\hline $\begin{array}{l}\text { L2e. Capacidad de elegir entre distintos sistemas } \\
\text { de representación y estilos en función de la } \\
\text { situación comunicativa, del tipo de contenido } \\
\text { para transmitir y del tipo de interlocutor. }\end{array}$ & 0 & 0 & 0 & 7 & 7 & 3 & 7,20 \\
\hline $\begin{array}{l}\text { L3e. Capacidad de modificar productos existentes, } \\
\text { confiriéndoles un nuevo sentido y valor. }\end{array}$ & 0 & 0 & 0 & 3 & 1 & 0 & 1,69 \\
\hline Total & 5 & 16 & 1 & 38 & 28 & 11 & 41,94 \\
\hline
\end{tabular}

CM: conocimiento del medio; EA: educación artística; EF: educación física; LC: lengua castellana y literatura; LE: lengua extranjera; MA: matemáticas.

Por su parte, en la dimensión 'Tecnología', las áreas del conocimiento del medio y educación artística ocupan el primer y segundo lugares, respectivamente, en cuanto a presencia de los descriptores de la competencia digital. A larga distancia, les siguen los contenidos de las áreas lingüísticas, o sea lengua castellana y literatura y lengua extranjera (Tabla 2). Los contenidos curriculares más significativos son los que se expresan a continuación de la Tabla 2.

- CN: utilización de recursos sencillos proporcionados por las TIC e Internet (T3a);

- $\quad$ EA: empleo de las TIC al tratamiento de imágenes, diseño y animación (T3e);

- EF: uso de las TIC para recabar información relacionada con la área, elaborar documentos y presentaciones, o sea juegos tradicionales, juegos del mundo, deportes, eventos deportivos (T2e); 
Tabla 2

Frecuencias y porcentajes totales de los descriptores de la dimensión "Tecnología".

\begin{tabular}{|c|c|c|c|c|c|c|c|}
\hline Descriptores & $\mathrm{CM}$ & EA & EF & LC & LE & MA & $\%$ \\
\hline \multicolumn{8}{|l|}{ Análisis } \\
\hline $\begin{array}{l}\text { T1a. Comprensión del papel que desempeñan } \\
\text { en la sociedad las tecnologías de la información y } \\
\text { de la comunicación y sus posibles efectos. }\end{array}$ & 7 & 1 & 0 & 0 & 0 & 1 & 3,81 \\
\hline $\begin{array}{l}\text { T2a. Habilidad para interactuar de manera } \\
\text { significativa con los medios que permiten } \\
\text { expandir las capacidades mentales. }\end{array}$ & 2 & 0 & 0 & 0 & 0 & 0 & 0,84 \\
\hline $\begin{array}{l}\text { T3a. Capacidad de manejar las innovaciones } \\
\text { tecnológicas que hacen posible una } \\
\text { comunicación multimodal y multimedial. }\end{array}$ & 2 & 1 & 0 & 2 & 2 & 0 & 2,96 \\
\hline \multicolumn{8}{|l|}{ Expresión } \\
\hline $\begin{array}{l}\text { T1e. Capacidad de manejar con corrección } \\
\text { las herramientas comunicativas en un entorno } \\
\text { multimedial y multimodal. }\end{array}$ & 2 & 0 & 0 & 2 & 1 & 0 & 2,11 \\
\hline $\begin{array}{l}\text { T2e. Capacidad de adecuar las herramientas } \\
\text { tecnológicas a los objetivos comunicativos } \\
\text { que se persiguen. }\end{array}$ & 2 & 1 & 1 & 0 & 0 & 1 & 2,11 \\
\hline $\begin{array}{l}\text { T3e. Capacidad de elaborar y manipular } \\
\text { imágenes y sonidos desde la conciencia de cómo } \\
\text { se construyen las representaciones de la realidad. }\end{array}$ & 0 & 9 & 0 & 0 & 0 & 0 & 3,81 \\
\hline Total & 15 & 12 & 1 & 4 & 3 & 2 & 15,67 \\
\hline
\end{tabular}

CM: conocimiento del medio; EA: educación artística; EF: educación física; LC: lengua castellana y literatura; LE: lengua extranjera; MA: matemáticas.

- LC: aplicación de las estrategias de consulta de enciclopedias y diccionarios (en soporte escrito e informático) o de la navegación por Internet para recoger información y realizar trabajos de forma individual o en equipo. Utilización de motores de búsqueda y foro para ampliar y dar sentido a los aprendizajes (T3a);

- MA: utilización de ordenadores, recursos TI y medios informáticos para el registro de datos reales en tablas, la visualización de diferentes tipos de gráficas estadísticas que ofrecen los programas informáticos y elección del más apropiado (T2e).

En cuanto a la dimensión 'Procesos de interacción', el área de educación artística encabeza la mayor relación con los descriptores de la competencia mediática, seguida de lengua castellana y conocimiento del medio (Tabla 3).

Como ejemplo se puede mencionar los siguientes contenidos curriculares: 
Tabla 3

Frecuencias y porcentajes totales de los descriptores de la dimensión "Procesos de interacción".

\begin{tabular}{|c|c|c|c|c|c|c|c|}
\hline Descriptores & CM & EA & EF & LC & LE & MA & $\%$ \\
\hline \multicolumn{8}{|l|}{ Análisis } \\
\hline $\begin{array}{l}\text { I1a. Capacidad de selección, de revisión y de } \\
\text { autoevaluación de la propia dieta mediática, en } \\
\text { función de los criterios conscientes y razonables. }\end{array}$ & 1 & 0 & 1 & 0 & 0 & 0 & 0,84 \\
\hline $\begin{array}{l}\text { I2a. Capacidad de dilucidar por qué gustan unos } \\
\text { medios, unos productos o unos contenidos, por } \\
\text { qué tienen éxito, individual o colectivamente: } \\
\text { qué necesidades y deseos satisfacen en lo } \\
\text { sensorial, en lo emotivo, en lo cognitivo, en lo } \\
\text { estético, en lo cultural, etc. }\end{array}$ & 2 & 4 & 0 & 0 & 0 & 0 & 2,54 \\
\hline $\begin{array}{l}\text { I3a. Capacidad de discernir y de gestionar las } \\
\text { disociaciones que se producen a veces entre } \\
\text { sensación y opinión, emotividad y racionalidad. }\end{array}$ & 0 & 2 & 0 & 0 & 0 & 0 & 0,84 \\
\hline $\begin{array}{l}\text { I4a. Capacidad de apreciar los mensajes provenientes } \\
\text { de otras culturas al diálogo intercultural en un } \\
\text { período de medios transfronterizos. }\end{array}$ & 0 & 0 & 0 & 2 & 0 & 0 & 0,84 \\
\hline $\begin{array}{l}\text { I5a. Capacidad de gestionar el ocio mediático } \\
\text { convirtiéndolo en oportunidad para el aprendizaje. }\end{array}$ & 0 & 0 & 1 & 0 & 0 & 0 & 0,42 \\
\hline \multicolumn{8}{|l|}{ Expresión } \\
\hline $\begin{array}{l}\text { I1e. Actitud activa en la interacción con las } \\
\text { pantallas, entendidas como oportunidad } \\
\text { para construir una ciudadanía más plena, un } \\
\text { desarrollo integral, para transformarse y para } \\
\text { transformar el entorno. }\end{array}$ & 0 & 0 & 0 & 1 & 0 & 0 & 0,42 \\
\hline $\begin{array}{l}\text { I2e. Capacidad de interaccionar con personas } \\
\text { y colectivos diversos en entornos cada vez más } \\
\text { plurales y multiculturales. }\end{array}$ & 0 & 0 & 0 & 1 & 1 & 1 & 1,27 \\
\hline Total & 3 & 6 & 2 & 4 & 1 & 1 & 7,20 \\
\hline
\end{tabular}

CM: conocimiento del medio; EA: educación artistica; EF: educación física; LC: lengua castellana y literatura; LE: lengua extranjera; MA: matemáticas.

- CM: necesidad de controlar el tiempo de ocio, entretenimiento con las TIC, televisión, videoconsolas, así como su poder de adicción (I5a);

- EA: observación y valoración del uso de música en medios de comunicación y/o audiovisuales y digitales, o sea, televisión, publicidad, cine, videojuegos y programas informáticos (I2a);

- EF: identificación de crítica de las prácticas poco saludables (sedentarismo, abuso del ocio audiovisual, adicción a las nuevas tecnología) (I1a); 
Tabla 4

Frecuencias y porcentajes totales de los descriptores de la dimensión "Procesos de producción y difusión".

\begin{tabular}{|c|c|c|c|c|c|c|c|}
\hline Descriptores & $\mathbf{C M}$ & EA & EF & LC & LE & MA & $\%$ \\
\hline \multicolumn{8}{|l|}{ Análisis } \\
\hline $\begin{array}{l}\text { P1a. Conocimiento de las diferencias básicas entre } \\
\text { las producciones individuales y las colectivas, entre } \\
\text { las populares y las corporativas, y, en el ámbito de } \\
\text { estas últimas, si es el caso, entre las elaboradas por } \\
\text { instancias de titularidad pública y privada. }\end{array}$ & 1 & 0 & 0 & 0 & 0 & 0 & 0,42 \\
\hline $\begin{array}{l}\text { P2a. Conocimientos básicos sobre los sistemas } \\
\text { de producción, las técnicas de programación y } \\
\text { los mecanismos de difusión. }\end{array}$ & 1 & 0 & 0 & 0 & 0 & 0 & 0,42 \\
\hline \multicolumn{8}{|l|}{ Expresión } \\
\hline $\begin{array}{l}\text { P1e. Conocimiento de las fases de los procesos } \\
\text { de producción y de la infraestructura necesaria } \\
\text { para producciones de caracteres personal, } \\
\text { grupal o corporativo. }\end{array}$ & 1 & 2 & 0 & 3 & 2 & 0 & 3,38 \\
\hline $\begin{array}{l}\text { P2e. Capacidad de trabajar, de manera } \\
\text { colaborativa, en la elaboración de productos } \\
\text { multimedia o multimodales. }\end{array}$ & 0 & 2 & 0 & 1 & 1 & 0 & 1,69 \\
\hline $\begin{array}{l}\text { P3e. Capacidad de seleccionar mensajes } \\
\text { significativos, apropiarse de ellos y } \\
\text { transformarlos para producir nuevos significados. }\end{array}$ & 0 & 0 & 0 & 3 & 0 & 0 & 1,27 \\
\hline $\begin{array}{l}\text { P4e. Capacidad de compartir y diseminar } \\
\text { información, a través de los medios tradicionales } \\
\text { y de las redes sociales, incrementando la } \\
\text { visibilidad de los mensajes, en interacción con } \\
\text { comunidades cada vez más amplias. }\end{array}$ & 2 & 2 & 0 & 3 & 2 & 0 & 3,81 \\
\hline Total & 5 & 6 & 0 & 10 & 5 & 0 & 11,01 \\
\hline
\end{tabular}

CM: conocimiento del medio; EA: educación artística; EF: educación física; $L C$ : lengua castellana y literatura; LE: lengua extranjera; MA: matemáticas.

- LC: valoración de los medios de comunicación social como instrumentos de aprendizaje y de acceso a informaciones y experiencias de otras personas, usando la información tanto en la vida escolar como social, así como de contribución a la formación como ciudadanos (I1e).

En lo que concierne a la dimensión 'Procesos de producción y difusión', la lengua castellana y literatura es la que mayor vinculación mantiene con la competencia mediática. El segundo lugar lo ocupa la educación artística, seguida de lengua extranjera y conocimiento del medio (Tabla 4). 


\section{Tabla 5}

Frecuencias y porcentajes totales de los descriptores de la dimensión "Ideología y valores".

\begin{tabular}{|c|c|c|c|c|c|c|c|}
\hline Descriptores & $\mathbf{C M}$ & EA & EF & LC & LE & MA & $\%$ \\
\hline \multicolumn{8}{|l|}{ Análisis } \\
\hline $\begin{array}{l}\text { V1a. Capacidad de evaluar la fiabilidad de las fuentes } \\
\text { de información, extrayendo conclusiones críticas } \\
\text { tanto de lo que se dice como de lo que se omite. }\end{array}$ & 1 & 0 & 0 & 5 & 2 & 0 & 3,38 \\
\hline $\begin{array}{l}\text { V2a. Habilidad para buscar, organizar, } \\
\text { contrastar, priorizar y sintetizar informaciones de } \\
\text { distintos sistemas y diferentes entornos. }\end{array}$ & 5 & 2 & 1 & 8 & 4 & 1 & 8,89 \\
\hline $\begin{array}{l}\text { V3a. Capacidad de detectar las intenciones o } \\
\text { intereses que subyacen tanto en las producciones } \\
\text { corporativas como en las populares, así como } \\
\text { su ideología y valores, explícitos o latentes, } \\
\text { adoptándose una actitud crítica ante ellos. }\end{array}$ & 3 & 3 & 0 & 4 & 3 & 1 & 5,93 \\
\hline $\begin{array}{l}\text { V4a. Capacidad de analizar las identidades } \\
\text { virtuales individuales y colectivas, y de detectar los } \\
\text { estereotipos, sobre todo en cuanto a género, raza, } \\
\text { etnia, clase social, religión, cultura, discapacidades, } \\
\text { etc., analizando sus causas y consecuencias. }\end{array}$ & 0 & 0 & 0 & 1 & 0 & 0 & 0,42 \\
\hline $\begin{array}{l}\text { V5a. Capacidad de reconocer los procesos de } \\
\text { identificación emocional con los personajes y } \\
\text { las situaciones de las historias como potenciales } \\
\text { mecanismos de manipulación o oportunidad } \\
\text { para conocernos mejor a nosotros mismos y } \\
\text { abrirnos a otras experiencias. }\end{array}$ & 0 & 1 & 0 & 1 & 0 & 0 & 0,84 \\
\hline $\begin{array}{l}\text { V6a. Capacidad de gestionar las propias } \\
\text { emociones en la interacción con las pantallas, } \\
\text { en función de la ideología y de los valores que se } \\
\text { transmiten en ellas. }\end{array}$ & 0 & 0 & 2 & 0 & 0 & 0 & 0,84 \\
\hline Total & 9 & 6 & 3 & 19 & 9 & 2 & 20,33 \\
\hline
\end{tabular}

CM: conocimiento del medio; EA: educación artística; EF: educación física; $L C$ : lengua castellana y literatura; LE: lengua extranjera; MA: matemáticas.

A continuación se propone una ejemplificación de los contenidos curriculares.

- CM: utilización del correo electrónico, de los sistemas de comunicación simultáneos, chat, entornos virtuales de comunicación con publicación de documentos e Internet (P4e);

- EA: la red como un contexto para la creación y difusión del arte (P4e);

- LC: producción de textos orales propios de los medios de comunicación social mediante simulación o participación para ofrecer y compartir información y opinión, intentando, de acuerdo con su nivel, dar argumentos en su exposición y manifestando sus sentimientos (P3e); 
Tabla 6

Frecuencias y porcentajes totales de los descriptores de la dimensión "Estética".

\begin{tabular}{|c|c|c|c|c|c|c|c|}
\hline Descriptores & $\mathbf{C M}$ & EA & EF & LC & LE & MA & $\%$ \\
\hline \multicolumn{8}{|l|}{ Análisis } \\
\hline $\begin{array}{l}\text { E1a. Capacidad de relacionar las producciones } \\
\text { mediáticas con otras manifestaciones artísticas, } \\
\text { detectando influencias mutuas. }\end{array}$ & 0 & 2 & 0 & 0 & 0 & 0 & 0,84 \\
\hline $\begin{array}{l}\text { E2a. Capacidad de identificar las categorías } \\
\text { estéticas básicas, como la innovación formal y } \\
\text { temática, la originalidad, el estilo, las escuelas } \\
\text { y las tendencias. }\end{array}$ & 0 & 1 & 0 & 0 & 0 & 0 & 0,42 \\
\hline \multicolumn{8}{|l|}{ Expresión } \\
\hline $\begin{array}{l}\text { E1e. Capacidad de producir mensajes elementales } \\
\text { que sean comprensibles y contribuyan a } \\
\text { incrementar los niveles personales o colectivos de } \\
\text { creatividad, originalidad y sensibilidad. }\end{array}$ & 0 & 3 & 0 & 0 & 0 & 0 & 1,27 \\
\hline $\begin{array}{l}\text { E2e. Capacidad de apropiarse y de } \\
\text { transformar producciones artísticas, } \\
\text { potenciando la creatividad, la innovación, la } \\
\text { experimentación y la sensibilidad estética. }\end{array}$ & 0 & 3 & 0 & 0 & 0 & 0 & 1,27 \\
\hline Total & 0 & 9 & 0 & 0 & 0 & 0 & 3,81 \\
\hline
\end{tabular}

CM: conocimiento del medio; EA: educación artística; EF: educación física; $L C$ : lengua castellana y literatura; LE: lengua extranjera; $M A$ : matemáticas.

- LE: composición de textos de variados tipos (notas, e-mails, mensajes de móviles, listas o esquemas), progresivamente más extensos, ricos en léxico y en estructuras lingüísticas (P4e).

En este análisis realizado, el área de lengua castellana y literatura muestra la mayor representación de la competencia mediática en los contenidos curriculares. En segundo lugar, Conocimiento del medio y Lengua extranjera también adquieren una importante vinculación de sus contenidos con los descriptores de la competencia. En la dimensión 'Ideología y valores', queda patente la presencia de la competencia en contenidos de todas las áreas del currículum del alumnado del cuarto de educación primaria, al igual que sucede en la mayor parte de las dimensiones (Tabla 5).

Los contenidos curriculares que proponemos como ejemplo son:

- $\mathrm{CM}$ : análisis como consumidores y usuarios de mensajes publicitarios (V2a);

- EA: aproximación al papel social y cultural de las exposiciones culturales, del cine, del teatro y de los medios de comunicación (publicidad, prensa, Internet) y de las producciones audiovisuales para informar, hacer pensar y persuadir (V3a); 
- LC: comprensión y reflexión contrastadas con los demás medios de información general en textos (escritos) procedentes de medios de comunicación social (radio, televisión, internet - incluidas redes infantiles y juveniles), con especial incidencia en la noticia y en las cartas al director, localizando informaciones destacadas en titulares, entradillas, portadas. Asimismo, han de iniciarse en la estructura básica del periódico y con especial incidencia en la noticia, la entrevista y las cartas al director, para obtener información general, localizando informaciones destacadas y comparando distintos medios (V1a);

- MA: análisis y uso crítico de la información obtenida en la red para realizar investigaciones y proyectos, y para expresarse y comunicarse, utilizando recursos y programas informáticos adecuados a cada finalidad, con autonomía personal y grupal (V3a).

Finalmente, en la dimensión 'Estética', la presencia de la competencia mediática se centra exclusivamente en educación artística, algo totalmente lógico al tratarse del ámbito de conocimiento propio del área. Junto con la dimensión 'Procesos de producción y difusión', existen contenidos de áreas que no se encuentran representados en la competencia analizada (Tabla 6).

Un ejemplo destacable podría ser la educación artística con el uso progresivo de imágenes de distintas fuentes, recursos, medios de comunicación, cromos y pegatinas en las producciones propias (E2e).

\section{Discusión y conclusiones}

El elevado componente educativo que se adjudica a los medios de comunicación ha originado que numerosas voces se levanten para que sean tratados de manera explícita en la escuela. Recientemente, Scheuer (2009, p. 15) ha apuntado que

desde hace más de 20 años, educadores de todo el mundo han hecho campaña a favor de la educación en medios; sin embargo, en la mayoría de los países, los responsables de las políticas educativas nacionales no han advertido hasta muy recientemente la importancia de la alfabetización mediática.

Nuestro sistema educativo, imbuido de la inercia europea y la antesala de una nueva reforma educativa (ESPAÑA, 2013), ha convertido a las competencias básicas en la columna vertebral del currículo escolar (TIANA, 2011), entendido de acuerdo con el artículo 5 del Real Decreto 1513/06 (ESPAÑA, 2006b), como "el conjunto de objetivos, competencias básicas, contenidos, métodos pedagógicos y criterios de evaluación de esta etapa educativa”. Si bien, la LOE de 2006 incorporó ocho competencias básicas al sistema educativo español en las enseñanzas 
primaria y secundaria, con la llegada de la Espańa (2013), dichas competencias se mantienen reformuladas como elementos curriculares que garantizan la adquisición de capacidades, destrezas y habilidades necesarias en la educación obligatoria.

Ha sido en los contenidos, un elemento tradicional de los currículos, en los que nos hemos centrado para delimitar la presencia o ausencia de la competencia mediática en el currículo del cuarto de educación primaria. En el análisis llevado a cabo, esta presencia se ha cifrado en un $65,45 \%$, lo que supone un porcentaje importante, en contraposición con las manifestaciones realizadas por diferentes autorías, tal y como recogíamos al inicio de estas páginas.

En este análisis estamos de acuerdo con lo manifestado por Tucho (2008), y pueden destacarse dos enfoques: el primero considera los medios de comunicación como instrumentos de apoyo a los procesos de enseñanza y aprendizaje; y el segundo entiende la necesidad de un análisis de estos desde una perspectiva crítica y desde su repercusión social.

El primer enfoque ha sido el que, de manera tradicional, se ha generalizado en el currículo escolar, quedando el segundo a la buena voluntad del profesorado. Sin embargo, propuesta presentada da un paso más en esta visión polarizada de la presencia de los medios de comunicación en las normativas estatal y autonómica. Al basarse en una delimitación de la competencia mediática en seis dimensiones y dos ámbitos de desarrollo, o sea análisis y expresión, se posibilita un análisis pormenorizado de la misma en los contenidos curriculares, destacando que:

- Si bien ni todos los descriptores de la competencia mediática quedan vinculados con los contenidos del currículo del alumnado del cuarto de educación primaria, todas las dimensiones quedan reflejadas en este elemento curricular.

- En todas las áreas se aprecia alguna relación entre los descriptores de la competencia mediática y los contenidos curriculares.

- En las dimensiones 'lenguajes, procesos de interacción e ideologías y valores', se predominan los procesos de análisis frente a los de expresión.

- En las dimensiones 'tecnologías, procesos de producción y difusión y estética', se destacan los procesos de expresión, en contraposición a los de análisis.

- En la dimensión 'ideología y valores’, sólo se contemplan procesos de análisis.

En definitiva, aunque la competencia mediática queda recogida en los contenidos curriculares, es necesario que esta se explicite aún más, de manera que el docente, en su proceso de concreción curricular, la identifique y seleccione los contenidos que posibiliten realmente poner en marcha programas de alfabetización mediática. 


\section{Notas}

1. Ver url: http://eur-ex.europa.eu/LexUriServ/LexUriServ.do?uri=OJ:L:2007:332:0027:0045:ES:PDF

2. Ver url: http://www.uhu.es/competenciamediatica/primaria/

3. Los maestros participantes fueron: Manuel J. Montilla, Cristina López, Ana María Granados, Diego Baena, Juana Sánchez, Antonio Saavedra, Carolina Moreno, María Dolores Montilla, Juan José López y Carlos A. García.

\section{Referencias}

AGUADED, J.I. et al. El grado de competencia mediática en la ciudadanía andaluza. Huelva: Grupo Comunicar Ediciones/Grupo de Investigación Ágora, Universidad de Huelva, 2011.

APARICI, R. et al. La educación mediática en la escuela 2.0. Madrid, 2010. Disponible en: $<$ http://ntic.educacion.es/w3/web 20/informes/educacion mediatica e20 julio20010. pdf>. Acceso en: 23 mar. 2012.

ARNAIZ, P.; DE HARO, R. Ciudadanía e interculturalidad: claves para la educación del siglo XXI. Educatio, n. 22, p. 19-37, 2004.

CAMPS, V. La educación en medios, más allá de la escuela. Comunicar, n. 32, p. 139$145,2009$.

DE LA ORDEN, A. Educación y competencias. Bordón. Revista de Pedagogía, v. 63, n. 1, p. 9-12, 2011.

ESPAÑA. Ley Orgánica 2/2006, de 3 de mayo, de Educación. Boletín Oficial del Estado, n. 106, 2006a.

. Real Decreto 1513/06, de 7 de diciembre, por el que se establecen las enseñanzas mínimas de educación primaria. Boletín Oficial del Estado, n. 293, 2006 b.

. Ley Orgánica 8/2013, de 9 de diciembre, para la mejora de la calidad educativa. Boletin Oficial del Estado, n. 295, 2013.

FERRÉS, J. La competencia en comunicación audiovisual: dimensiones e indicadores. Comunicar, n. 29, p. 100-107, 2007.

FERRÉS, J. et al. Competencia mediática. Investigación sobre el grado de competencia de la ciudadanía en España. Madrid: Ministerio de Educación, 2011.

FERRÉS, J.; PISCITELLI, A. La competencia en educación mediática: propuesta articulada de dimensiones e indicadores. Revista Comunicar, n. 38, p. 75-82, 2012.

GABELAS, J.A.; MARTA, C. Grado de Competencia en Comunicación Audiovisual de los aragoneses. Aragón: Consejo de Aragón, 2011.

GONZÁLEZ, N.; SEDEÑO, M.; GONZÁLVEZ, V. Diseño de un focus group para valorar la competencia mediática en escenarios familiares. Icono 14, v. 10, n. 3, p. 116-133, 2012. 
ORGANIZACIÓN PARA LA COOPERACIÓN Y EL DESARROLLO ACADÉMICO/ DESIGN AND SELECTION OF COMPETENCIES - OCDE-DESECO. Definition and Selection of Competencies: Theoretical and Conceptual Foundations. Bruselas, 2002. Disponible en: <http://www.oecd.org/pisa/35070367.pdf>. Acceso el: 25 mar. 2012.

ORTIZ, M. La construcción curricular de la Escuela Necesaria. Revista de Pedagogía, v. 30, n. 86, p 89-114, 2009.

SCHEUER, M. Prólogo. Comunicar, v. 16, n. 32, p. 15-16, 2009.

TIANA, A. Análisis de las competencias básicas como núcleo curricular en la educación obligatoria española. Bordón. Revista de Pedagogía, v. 63, n. 1, p. 63-75, 2011.

TUCHO, F. La educación en comunicación en la LOE y sus decretos de Enseñanzas Mínimas. Comunicar, n. 31, p. 547-553, 2008.

UNIÓN EUROPEA. Recomendación del Parlamento Europeo y del Consejo de 18 de diciembre de 2006 sobre las competencias clave para el aprendizaje permanente (2006/962/ CE). Diario Oficial de la Unión Europea, 2006. Disponible en: <http://www.mcu.es/ cine/docs/Novedades/Recomendacion Parlamento Europeo Consejo Aprendizaje permanente.pdf >. Acceso el 24 mar. 2012.

ZABALA, A.; ARNAU, L. 11 ideas clave. Cómo aprender y enseñar competencias. Barcelona: Graó, 2008.

Recibido en 07 de janeiro de 2014.

Aprobado en 20 de julio de 2015. 